\title{
LA DIDÁCTICA DE LA LITERATURA INGLESA CON TEXTOS POÉTICOS
}

\author{
Asunción Barreras Gómez \\ Universidad de La Rioja
}

\begin{abstract}
RESUMEN. Los distintos contactos con la literatura han de hacerse según la edad, actitudes, grado de preparación y motivación del alumno. No se debe provocar un desfase entre el lector y el texto para que el alumno no rechace la literatura. La integración se llevará a cabo en textos conexionados, en progresión creciente de dificultades y con unos temas adecuados. No es lo mismo un niño estudiante de inglés en primaria, que un alumno universitario. El profesor debe graduar los textos literarios de forma que los alumnos respondan correctamente a esos textos literarios. Esto supone que el docente tiene un amplio conocimiento literario y psicológico para poder elegir adecuadamente. Hay profesores que utilizan la literatura para que sus alumnos desarrollen su competencia lingüistica, para que aprendan sobre la cultura del país de esa lengua extranjera o para acercarlos al hábito de la lectura en ingles. Hay profesores que seleccionan aquellas obras literarias que sus alumnos pueden entender, ya que existen libros cuyo lenguaje o referencias culturales resultan dificiles de comprender para los alumnos. Los profesores tienen en cuenta estas características para crear las condiciones óptimas para el aprendizaje de los alumnos. Creando estas condiciones también se ayuda a los alumnos a que desarrollen esa competencia literaria necesaria para apreciar los estilos, formas, convenciones o símbolos de las obras.
\end{abstract}

ABSTRACT. A student's first contact with English literature should be done taking into account the age, attitude, level of English and motivation of the learner. The selected text should provide a balance between the reader and the text thus assuring that the text will not be rejected. The texts should be coherent and progressively difficult. They should also use topics which are appropriate to the student. Primary Education English pupils possess different characteristics from those of university students.

The teacher must also use graded literary texts so as to make both pupils and students respond in the desired manner. This is supposing that the teacher has a wide knowledge of literature and psychology and is thus able to choose the appropiate texts. Teachers use English literature for a variety of reasons these being improving linguistic competence, getting the students used to reading in English or to teach more about the country in question. There are also teachers who choose literary texts that their pupils will understand, the reason being that there are many books whose cultural references or language are too difficult for the pupils.

The teachers take all these features into account in order to be able to provide the optimum learning conditions for the pupils. In providing these conditions the pupils are also helped to develop their literary competence so that they will appreciate the different styles, forms, conventions or symbols that can be found in the texts. 


\section{Aproximación al tema}

Cuando se acerca un texto literario al alumnado el profesor debe seleccionarlo cuidadosamente. Hay factores que el profesor ha de tener en cuenta para que el alumno no rechace la literatura como la edad, el nivel de inglés, la motivación del alumno y su área de intereses. De esta forma, el profesor ayuda a que sus alumnos desarrollen su competencia literaria con la que puedan comprender y apreciar la obra literaria. Brumfit y Carter (1986, p. 18) definen la competencia literaria como "an interesting combination of linguistic, socio-cultural, historical and semiotic awareness." Al adquirir esta competencia los alumnos desarrollan una sensibilidad especial para apreciar el uso de la lengua. De hecho, al seleccionar los textos el profesor debe tener en cuenta como uno de sus objetivos didácticos que sus alumnos adquieran la competencia literaria. Además, hay que tener en cuenta que no es lo mismo formar al alumno para que disfrute y valore las obras literarias que transmitirle una serie de conocimientos sobre esas creaciones literarias sin que tengan un contacto directo con la obra. El estudio literario implica la lectura de textos literarios. En la selección de textos literarios que haga el profesor tendrá que tener en cuenta otros factores. Serán textos que el estudiante pueda entender desde el punto de vista lingüístico, pero que también los pueda entender por estar próximos a sus experiencias. Hay profesores que creen en los aspectos positivos que tienen las versiones simplificadas o modernizadas ya que les resultan más fáciles de comprender a los estudiantes. Sin embargo, esto no garantiza que vaya a gustar a los alumnos. Hay que analizar cómo está hecha esa simplificación o modernización, si está bien construida, si resulta interesante, etc. (Carter \& Long 1991, p. 6). Hay versiones adaptadas o modernizadas que lingüísticamente pueden resultar más fáciles a los alumnos, pero les falta cohesión y comprensión respecto a la obra literaria primaria. Por otro lado, hay que tener en cuenta el nivel de inglés del alumno. Puede haber alumnos con un alto nivel de inglés que pueden leer los textos originales, como es el caso de los alumnos de Magisterio de la especialidad de lengua inglesa y Filología inglesa. Además, la mejor opción es ofrecer el texto original ya que cualquier cambio supone una "interposición creación-lector" (Escudero Martínez 1994 , p. 56) que es preferible no crear para que el alumno acceda a la totalidad de la obra. Por otro lado, la ventaja que presenta el uso de un texto original es que proporciona ejemplos reales en lengua inglesa. De esta forma el alumno puede adquirir inconscientemente vocabulario o giros gramaticales a la vez que desarrolla su sentido estético literario. Otros profesores prefieren usar antologías. En una antología se encuentran distintos textos reunidos que son ejemplos de todas las épocas y géneros literarios. Además tienen buenas introducciones sobre las características de las obras para facilitar su comprensión y estudio e incluyen notas aclaratorias sobre cualquier dificultad con la que el alumno se pueda encontrar. El problema que puede plantear el uso de las antologías es el fragmentarismo que presenta en las obras narrativas y dramáticas, que puede llevar a la dispersión al lector, aunque en las obras poéticas este hecho no sea relevante.

Como durante un curso no se puede leer todas las obras pertenecientes a la literatura inglesa, el profesor debe diseñar su temario y una selección de lecturas. Aunque en otros tiempos pudieran seleccionarse los textos literarios debido más a las tradiciones e intereses de los profesores que a los intereses de los alumnos; hoy en día los 
profesores seleccionan los textos de acuerdo con los intereses del alumno y teniendo en cuenta sus posibilidades de comprensión, por tanto el profesor debe conocer a sus alumnos, edad, limitaciones y necesidades. Esto es debido a que un temario de literatura inglesa sólo se puede dar cuando los alumnos poseen un mínimo de competencia lingüística para que puedan comprender la obra. Estudiando los tipos de textos y la psicología de los receptores, Northrop Frye (1973, p. 173), interesado por cuestiones de la didáctica de la literatura, sugiere para los primeros niveles los tonos románticos y cómicos, mientras que lo trágico e irónico sería para los receptores mayores. Esta idea puede ser válida con los alumnos de Educación Primaria. Sin embargo, no lo es con los alumnos universitarios que deben adquirir una visión general de la literatura inglesa. Además, el criterio de selección variará no sólo debido a las necesidades de los alumnos sino también debido al tipo de temario que se quiera adoptar. El temario puede tener distintos objetivos: la historia de la literatura, la adquisición de la competencia lingüística, conocimiento de la cultura y la tradición de ese país, etc. Por otro lado, el profesor debe trabajar con todo tipo de procedimientos para que los alumnos se impliquen y participen activamente en la literatura. Aunque el problema que puede surgir con estos textos tanto para los lectores nativos de inglés como para los no nativos es que no den una buena respuesta literaria por no tener una cierta fluidez de lectura y una buena comprensión del texto.

\section{Selección de un texto literario inglés}

William Littlewood (1986, p. 180) proporciona cinco perspectivas distintas para la selección de textos. En la primera se ve la literatura como un conjunto de estructuras lingüísticas. Si el alumno supera estas estructuras lingüísticas éste puede apreciar la obra literaria. El segundo criterio que marca es la corrección estilística, con lo que el profesor debe elegir aquellos textos apropiados desde ese punto de vista. La tercera perspectiva es elegir esos textos literarios que resulten interesantes para los alumnos y que puedan entender con el bagaje cultural que poseen. La cuarta perspectiva es la que tiene en cuenta el nivel lingüístico e intelectual del alumno así como su motivación para leer ese libro. La quinta perspectiva es elegir aquellos textos relevantes debido a su lugar en la historia literaria o en un movimiento literario. Para ello los alumnos necesitan tener un amplio conocimiento de la literatura y el contexto en el que esa obra surge.

Con los alumnos de Educación Primaria se utilizan textos literarios como cuentos, limericks y nursery rhymes parta introducirles un nuevo tipo de vocabulario y expresiones o como revisión de lo aprendido en unidades anteriores. Sin embargo, los alumnos universitarios se encuentran en esa quinta situación mencionada, de elegir aquellos textos relevantes debido a su lugar en la historia literaria o en un movimiento literario, con la asignatura de literatura inglesa. Se les presentan unas obras literarias representativas de cada movimiento junto con información literaria sobre esa obra, ese periodo y el autor para que entiendan mejor la obra. Durante mucho tiempo se ha venido utilizando el historicismo como modelo de la didáctica de la literatura aplicable en la clase. Pero lo que el profesor debe hacer es activar un aprendizaje significativo de la literatura en el alumno y su espíritu crítico; de tal forma que la acti- 
vidad constructiva se apoye en unos esquemas previos que vayan incorporando nuevos elementos y vayan modificando ese esquema, transformándolo y ampliándolo. En este sentido cabe destacar el hecho de que cuando nuestros alumnos de Magisterio de la especialidad de la lengua inglesa o de Filología inglesa se enfrentan, por primera vez, con un texto literario inglés ya tienen suficientes conocimientos de la lengua inglesa para poderlo entender y también conocen diversos periodos e influencias literarias importantes en Europa por las clases de literatura española que ya han recibido.

\section{Estrategias y situaciones en la clase}

Las estrategias a las que se puede recurrir en las clases son varias. La estrategia planificada marca una serie de acciones lineales. La cíclica pone en funcionamiento mecanismos de realimentación y se revisan etapas anteriores. En la estrategia de ramificación las etapas diseñadas son paralelas o alternativas. En la adaptable se decide, se cambia o diseña la estrategia dependiendo de las experiencias y conocimientos manifestados en la clase. La estrategia incremental vuelve a valorar la estrategia existente y explora las modificaciones menores que se pueden hacer. Finalmente, en la fortuita se selecciona un problema y se define a partir del esquema diseñado. La forma más adecuada resulta la cíclica ya que, como destaca Martos (1988, p. 91) siguiendo las directrices de Ausubel (1979), la información nueva no es asimilada por el alumno si no va acompañada de inclusores, es decir, elementos que sirven de puente entre la información conocida y la desconocida. Esto se consigue más claramente con la estrategia cíclica. Sin embargo, la estrategia adaptable resulta muy práctica porque se puede cambiar teniendo en cuenta las respuestas que dan los alumnos ya que la instrucción es un proceso cambiante.

Aparte de las estrategias que el profesor decida utilizar en su clase por ser más operativas, en una clase en la que se utilice la literatura inglesa se pueden dar estas tres posibles situaciones:

1. students working in their mother tongue on literature, with a great deal of aesthetically structured speech and children's writing behind them;

2. students working through a foreign or second language coming from a culture with a well-developed literary tradition, with which they are already slightly familiar. . .

3. students working through a second language whose experience of artistically organized language is primarily oral, and whose culture may indeed have very different assumptions from those of western Europe . . . about aesthetics and language. (Brumfit \& Carter 1986, pp 29-30)

El primer grupo son los que más están desarrollando su competencia lingüistica y literaria. Los del segundo grupo entran en contacto con la literatura inglesa cuando ya tienen un cierto conocimiento de la lengua inglesa y de la literatura en su propia lengua. Este es normalmente el caso de los alumnos universitarios españoles. En último lugar, el tercer grupo de alumnos aprenden la lengua por motivos educacionales e instrumentales, pero carecen de una tradición escrita en su literatura y la encuentran en la literatura inglesa. 


\section{La literatura inglesa en las clases de inglés}

Los alumnos de Primaria no entrarían en ninguna de estas clases ya que su contacto con la literatura se hace de modo indirecto. De esta forma, les sirve de ejemplo de input de forma entretenida. Cuando a estos alumnos se les introduce la literatura se hace por medio de la poesía del tipo nursery rhymes y limericks, pertenecientes a lo folklórico y tradicional. Se trata de piezas cortas que el alumno puede seguir fácilmente precisamente por su breve capacidad de concentración y, además, son obras de un gran ritmo, lo que les resulta más fácil de recordar. Otro recurso es el cuento que lo pueden oír al leérselo la maestra o lo puede ver representado en un vídeo o en una obrita de teatro interpretada por ellos mismos para que se vean implicados en lo que están haciendo. Aparte Cervera (1993, p: 15) destaca cuatro formas de acercar los niños a la literatura. La primera es por vía auditiva, la segunda por medio del juego, la tercera utilizando la expresión y la última por medio de la creación de textos. Sin embargo, esta última técnica sólo se utiliza oralmente con los alumnos de Educación Primaria ya que si todavía no han aprendido a utilizar las destrezas escritas en su lengua materna mucho menos las habrán aprendido en una lengua extranjera, especialmente para crear un nuevo texto en esa lengua extranjera que están aprendiendo.

A la hora de seleccionar los textos el maestro puede tener diferentes objetivos; diversos críticos han expresado sus ideas sobre los objetivos que se puede plantear un maestro con sus alumnos de Educación Primaria. El esquema de Cervera (1993, p. 18) muestra varios objetivos. El lingüístico tiene que ver con que el alumno descubra la lengua. El imaginario pretende que el alumno potencie su imaginación con la dimensión creativa del texto. El lúdico sirve para aprovechar el aspecto lúdico de la literatura. Con el expresivo los alumnos captan modelos expresivos para comunicarse. El último es el cultural con el que el alumno participa de otra cultura. Otros críticos como Ellis y Brewstwer (1991, p. 11) desarrollan un esquema de objetivos diferente para seleccionar un texto para niños. El primero es el lingüístico con el que el alumno adquiera vocabulario, pronunciación y nuevos contenidos. El segundo es el psicológico para, a través de ayudas visuales como las imágenes de colores vivos o provocando la curiosidad, los alumnos se motiven y participen. El último es el cultural por el que, creando actitudes positivas hacia la cultura de la lengua extranjera, los niños conozcan esa nueva cultura y, poco a poco, se vayan dando cuenta de la existencia de otras culturas tan válidas como la propia. Con todo ello se pretende enriquecer al niño con recursos expresivos y conocimientos culturales de esa lengua que está aprendiendo a la vez que se le motiva en lo que está haciendo.

Para alumnos de niveles más altos de inglés, como ocurre en las clases de escuela de idiomas, Magisterio de la especialidad de lengua inglesa o Filología inglesa, Michael Long (1986, p. 54) destaca distintas formas de dar las clases. La primera es la clase magistral. El profesor domina la situación y no hay interacción entre el profesor y los alumnos. Es un proceso unidireccional ya que la única respuesta que se espera de los alumnos es un trabajo de investigación. Hay un segundo modo, multidireccional. El profesor les da información sobre el texto que están estudiando. Esa información es breve, relevante y hace mucha referencia al texto de tal forma que los alumnos lo puedan entender. Se realizan preguntas tanto por parte del profesor como por parte de los alumnos y tiene lugar la interacción entre ambos y como el ejemplo anterior la clase 
está centrada en el profesor. Esto no ocurre en la tercera propuesta que está basada en el alumno y que se llama preparación de actividades. El profesor establece las tareas que se han de hacer. Los alumnos las trabajan en grupos y controlan cómo van progresando en lo que hacen. Esta actitud se ve favorecida por el uso que se está haciendo del enfoque comunicativo en la enseñanza del inglés que promueve las actividades en grupo y la interacción alumno-alumno. Normalmente se suele adoptar una postura intermedia en las aulas universitarias. El profesor da información sobre un obra literaria que puede facilitar con fotocopias o indicaciones en la pizarra. Así los alumnos reciben información sobre una época, una tradición o un autor y pueden centrar el texto que tienen que leer. Luego se les proporciona actividades individuales o de grupo hasta que los alumnos se acostumbren a registrar las características específicas del texto. De esta forma, los alumnos practican el reconocimiento de esas características, a la vez que se favorece una interacción alumno-alumno y un ambiente de colaboración entre ellos. Mientras tanto el profesor va de grupo en grupo ayudando o sugiriendo.

Se está dejando atrás la figura del magister dixit de antaño. Ahora el profesor selecciona los textos y las actividades (de acuerdo con las necesidades y actitudes de sus alumnos), específica los objetivos, diseña los procedimientos, elige medios, ayuda a sus alumnos, potencia sus aptitudes, les anima y les motiva. El profesor ya no es un dogmático y no necesariamente tiene un papel protagonista en la clase. Las cłases se pueden centrar en los alumnos y el papel del profesor pasa a ser el de un colaborador dialogante. Además, ahora el profesor se concentra en el texto literario, dejando atrás aquellos días en los que el profesor se limitaba a dar información sobre los textos literarios. Para ello el profesor debe tener una formación literaria correcta y debe saber emplear el método más adecuado dependiendo de sus alumnos para lograr la correcta comprensión de los textos. El profesor parte del hecho literario para que los alumnos adviertan los aspectos teóricos de esa obra y para mostrar las críticas fundamentales de ese hecho literario. Pero debe tener en cuenta los niveles de recepción y de degustación de los textos literarios por parte de sus alumnos.

\section{El texto poético inglés en las clases}

La poesía es la obra o composición en verso, y normalmente pertenece al género lírico, aunque las obras épicas y dramáticas también fueron escritas en verso en un principio. El lenguaje lírico que muestra esta composición es la manifestación de una emoción subjetiva o un sentimiento. El tema del poema requiere concentración para conseguir la máxima intensidad del poema, que se logra en parte por la utilización de determinadas palabras, estructuras y tonos. Otra característica de la poesía es el uso de los símbolos y sus significados que le pueden hacer tan sorprendente. En estos usos simbólicos se encierra la temática del poema con mucha frecuencia: la vida, la muerte, la soledad, etc. También es importante la expresión que utiliza el poeta en el poema. Se ha de valorar cualquier uso sintáctico o léxico anómalo, las peculiaridades que ponga de relieve, cualquier uso significativo, etc. El comentario de texto sirve para darse cuenta de las características, señalar aspectos determinados, destacarlos y explicarlos. Utilizar textos poéticos no significa el almacenamiento de información recogi- 
da en clase sino que el alumno conozca por sí mismo y valore los textos que los autores han escrito. Esto facilita el comentar los textos literarios. Su utilización fomenta las facultades del desarrollo mental: la comprensión oral y escrita, el pensamiento analítico y sintético, la creatividad y el uso de los metalenguajes de las diversas disciplinas y técnicas de trabajo intelectual como destaca Martos (1988, p. 167). Esto es lo que deberían hacer los alumnos de niveles avanzados, como los de Magisterio de la especialidad de lengua inglesa o Filología inglesa, a la hora de analizar un texto en verso durante una clase de comentario de textos.

La técnica del comentario de textos se puede sistematizar con una serie de preguntas sobre el texto que se graduarán dependiendo del tipo de alumnos con los que estemos hasta conseguir que los alumnos lo analicen por sí solos. Hay que tener en cuenta que el profesor puede dirigir los pensamientos y las conclusiones de los alumnos por medio de sus preguntas o explicaciones. Lo que el profesor debe hacer es permitir todo tipo de explicaciones basadas en el texto literario para que el alumno piense y recree el texto con su lectura.

No existe una única metodología para comentar un texto, pero un esquema muy general para comentar un texto literario es, por ejemplo, el siguiente: lectura del texto, localización y clasificación del texto, exposición de la idea principal y discernimiento de las ideas accesorias, análisis y comentario del texto y valoración del texto. Se pueden utilizar distintos puntos de vista para analizarlo. El formalista estudia el texto en sí mismo. La psicocrítica busca las características y rasgos de la personalidad del autor. La sociocrítica ve el texto literario como un lugar donde quedan plasmadas las realidades y costumbres de una época histórica. Hay toda una literatura de crítica literaria que sustenta cada enfoque con el que se estudia un texto. Todos estos libros ayudan a estudiar y analizar una obra literaria. Este tipo de bibliografía la puede utilizar el alumno universitario cuando tiene que escribir un trabajo analizando una obra y en el que tiene que desarrollar una tesis. Sin embargo, no necesita este tipo de bibliografía cuando se trata de analizar textos en clase y de lo que se trata es de que entiendan el texto y lo analicen ellos mismos. En estos casos de lo que se trata es de que tomen como base el texto para comentarlo. Así es como entiende el comentario de textos Lázaro Carreter "se centra en el discurso escrito como base referencial y pretende dar cuenta de las peculiaridades lingüísticas y expresivas que lo configuran" (García y Medina 1988, p. 562). Esto es lo que tienen los alumnos al enfrentarse a un texto que tienen que explicar.

Por otro lado, existe una amplia variedad de estrategias para la enseñanza de la lengua inglesa usando un texto literario poético. El alumno no tiene que desarrollar su competencia literaria especialmente sino entender el texto poético para poder hacer las actividades. Estas actividades se graduarán de acuerdo con el nivel de inglés de los alumnos y sus características.

Una estrategia es la predicción. Con ella se deja a los alumnos leer el texto poético, pero tienen que parar en determinados momentos para predecir lo que viene después. Lo pueden hacer en grupos o parejas, justificando su elección, por lo que tienen que hablar entre ellos. Es una manera de motivarles y de que entiendan el texto poético para poder hablar en inglés. La utilización del cloze o texto mutilado también tiene que ver con la predicción. Este ejercicio está basado en dos teorías mentalistas, la teoría de la completez o clausura - la mente humana tiende a dar forma, a comple- 
tar- y la teoría de la anticipación - la percepción de elementos aislados anticipa hipótesis en forma de bloques semánticos- $y$, por último, también está basada en una hipótesis lingüista, la redundancia lingüística (Alcaraz 1993, p. 69). El alumno tiene que deducir de qué palabra se trata, teniendo en cuenta los datos que tiene en el texto poético y sus propios conocimientos. El objetivo de este tipo de ejercicios es llamar la atención sobre el uso particular de características lingüísticas como, por ejemplo, los conectores. Para elegir cualquier palabra hay que tener en cuenta todo el texto poético y si realmente concuerda con el resto de las palabras. El alumno tiene que desarrollar una cierta sensibilidad hacia las palabras.

Otra actividad en la línea de hacer consciente a los alumnos del lenguaje literario es que los alumnos parafraseen partes del texto poético, lo que implica volver a exponer las mismas ideas con distintas palabras. Los alumnos practican su expresión escrita, pueden cambiar de estilo, elegir el vocabulario, con estas elecciones los alumnos se dan cuenta de la intención comunicativa del escritor. Otra actividad es escribir creativamente en inglés, tomando el tema que trate el texto poético. Por ejemplo, se les da un par de versos a los alumnos y tienen que acabar el poema.

Un texto poético puede servir como base para crear un debate en la clase sobre un tema en el que pueden intervenir todos los alumnos. Este ejercicio sirve de estímulo para la práctica de la destreza del habla. Otra forma de practicar esta destreza es la lectura en voz alta de un poema. Los alumnos pueden leerlo con lo que deben practicar su pronunciación. También los maestros pueden leerlo para que sus alumnos practiquen la escucha. Una buena lectura de un poema puede hacerlo comprensible aunque no se entiendan sus palabras. Sin embargo, pocos maestros practican esta técnica que puede ser tan útil para la comprensión del alumno (Carter \& Long 1991, p. 82).

Otra forma de practicar la comprensión de un poema es el ordenar una serie de estrofas desordenadas del poema. Los alumnos tienen que organizarlo de tal forma que tenga sentido. Pero este tipo de actividades se graduarán de acuerdo con el nivel de los alumnos ya que esta actividad se puede organizar de otras formas, por ejemplo, teniendo que casar estrofas donde aparezca un lugar o un personaje con dibujos o fotografías o casar poemas con títulos etc.

\section{Los textos poéticos en las clases de educación primaria}

Sin embargo, en las clases de inglés en la Educación Primaria, el uso de poesía se debe enfocar de otra forma. Los poemas (del tipo nursery rhymes y limericks) ofrecen al maestro de Primaria un rico recurso y un gran repertorio lleno de rimas, reiteraciones y ritmos para el alumno. La brevedad del poema facilita su análisis y su explotación durante una hora de clase, dependiendo del nivel del alumno. Son textos que, a pesar úe su brevedad, muestran un amplio número de imágenes de gran efecto y una estructura rítmica que facilita su memorización. Son composiciones de diversa índole, de distintos contenidos, normalmente breves y de origen popular. Sus orígenes, como los de toda literatura popular y anónima, son difíciles de saber. Se caracterizan por la musicalidad. El ritmo queda determinado por la distribución de acentos y pausas. El tono y la acentuación y, especialmente, el ritmo facilitan el aprendizaje de una poe- 
sía "hasta el punto de que los niños son capaces de retener de memoria retahílas o estribillos carentes de significado, pero dotados de sonoridad y de ritmo" (Cervera 1993, p. 172). La brevedad y sencillez facilitan el aprendizaje del poema así como que el nivel de dificultad de la pieza sea bajo. Leer o escuchar poesía desarrolla el gusto por la belleza, mejora el conocimiento y uso del lenguaje así como fomenta la sensibilidad y la imaginación. La introducción de la poesía en la clase de inglés de primaria se debe hacer de una forma motivadora: decorando la clase de forma especial, recreando y explicando el poema, ilustrando el poema plásticamente y musicalmente, de tal forma que el poema se convierta en un juego o una diversión.

Al trabajar un poema el maestro puede tener distintos objetivos: percibir los sonidos, el ritmo, la rima en el inglés, deducir el significado de las palabras con las ilustraciones que muestre a los alumnos etc. Los niños entran en contacto con la sensibilidad de la poesía, el ritmo, las ideas y metáforas que pueden plasmar en imágenes y memorizar sus versos. Se pueden destacar las palabras nuevas y trabajarlas en actividades que se propongan junto con ese poema. Se pedirá la participación de los alumnos en estas actividades y dependerá de lo siguiente: la edad de los niños, el ambiente, la dificultad del ejercicio etc. Pueden ser juegos de movimiento, dramatizaciones, danzas o actividades centradas en el lenguaje del texto. Críticos como Wright (1996), Collie y Slater (1994), Lott (1986), Carter y Long (1991) etc. hacen su propuesta de actividades basadas en un poema, que se podrán ajustar a las características del alumno y su nivel. Actividades de este tipo son: crear rimas de palabras que rimen con los nombres de animales: fish-dish, mice-ice, mouse-house, choral reading del poema, hacer metáforas relacionadas con el poema, hacer dos columnas de palabras (las que suenan bien y mal) del poema, etc. Lo importante es que el maestro sepa cuales son los objetivos que quiere conseguir con el poema, elija el poema adecuado y diseñe unas actividades correctas y acordes con esos objetivos y actividades motivadoras para los alumnos.

\section{Conclusiones}

La enseñanza de la literatura en clase debe tender a crear lectores como objetivo principal. La formación literaria de alumnos universitarios incluye interpretar y analizar obras literarias inglesas concretas. Sin embargo, en las aulas de Educación Primaria, se debe ser consciente de la parte lúdica de la literatura y saber apreciarla. En este sentido es importante la didáctica de la literatura inglesa. Los alumnos universitarios desarrollan su competencia literaria leyendo diferentes textos literarios ingleses que les hacen conocer la cultura, la historia y la sociedad inglesa así como le suponen un ejemplo de input y de práctica de inglés al tener que leer las obras en la lengua original. En las clases de literatura pueden ver cómo el profesor les aproxima al texto, dando una introducción sobre la obra, haciendo preguntas, recomendando alguna versión fílmica basada en esa obra literaria, etc. El gran recurso para analizar e interpretar un texto poético es el comentario. Los comentarios de textos literarios ingleses en las clases universitarias suelen ser muy ricos debido al nivel intelectual de los alumnos, la información ofrecida por el profesor y la participación en clase. Otras estrategias relacionadas con la literatura y con las que el alumno de Magisterio se ve familiarizado es usar un texto literario para la enseñanza del inglés. Pero este tipo de actividades se desarrollan en las clases de inglés 
y no en las de literatura inglesa propiamente. Además de estas estrategias que acercan el alumn̈o universitario al texto literario inglés, éste debe conocer otras estrategias. Esto pertenece al campo de la didáctica de la literatura que ayuda a cómo usar textos literarios ingleses en las clases de Primaria. Se tiene que graduar, para los alumnos de Primaria, las estrategias que ya le son conocidas (la aproximación al texto literario y las estrategias para la enseñanza de la lengua usando un texto literario ya que el comentario de textos no se podría trabajar con unos niños de tan corta edad y de bajo nivel de abstracción) y conocer otras ayudas que le sirvan en la clase de primaria: el taller literario, el tebeo, la dramatización o el teatro de títeres.

El uso de textos poéticos en una clase de Primaria de inglés acerca al niño a la cultura del país de la lengua extranjera. Este recurso ayuda a comprender y respetar las otras culturas distintas a la propia y posibilita un mejor entendimiento entre todas las culturas de la Unión Europea. Para acercar los textos poéticos ingleses al joven estudiante de Primaria se utilizan procedimientos similares a aquellos en los que el niño se desenvuelve en su lengua materna. El uso de este recurso favorece el progreso del aprendizaje ya que activa mecanismos inconscientes en el alumno para que adquiera la lengua extranjera puesto que éste no centra sus esfuerzos en el código lingüístico sino en la comprensión del contenido. El uso de poemas pertenece al campo de intereses del alumno de Primaria y supone un ejemplo de input comprensible para el niño ya que el maestro se puede ayudar de elementos visuales, gestos o cambios de voz para hacerse comprender. De esta forma el niño activa y desarrolla sus propios mecanismos de aprendizaje. Como consecuencia de la utilización de este recurso el ambiente que se consigue en clase es distendido y esto facilita el aprendizaje de los alumnos.

El uso de poemas supone la práctica en las clases de inglés de las destrezas orales tan importantes en Primaria. Esto es debido al hecho de que como un niño en esta etapa no domina las destrezas escritas en su propia lengua nativa difícilmente lo conseguirá en la lengua extranjera. Por eso las destrezas orales son el objetivo principal de la Educación Primaria. El texto escrito sólo tendrá la función de soporte de la imagen o de la palabra pronunciada.

Otro objetivo importante que hay que destacar en esta etapa es el conseguir que los alumnos sean comunicativamente competentes. En este sentido es importante el uso de recursos no lingüísticos como gestos, posturas corporales o dibujos porque les sirven para hacerse comprender. Este recurso lo pueden trabajar con las dramatizaciones o con cualquier actividad que tenga que ver con la mímica a la hora de trabajar el poema.

El maestro debe crear las condiciones adecuadas para que tenga lugar la adquisición de la competencia comunicativa de los alumnos utilizando todos los recursos posibles. Por eso debe saber cómo elegir un texto literario, cómo atraerles a él, qué recursos materiales utilizar, qué estrategias utilizar y cómo graduarlas.

\section{Bibliografía}

AlCARAZ, Enrique (1993). "La lingüística y la metodología didáctica de las lenguas extranjeras" en García Hoz 1993: 19-109.

BRUMFIT, Christopher and CARTER, Ronald. (1986). Literature and Language Teaching. Oxford: Oxford U.P. 
CARTER, Ronald \& LONG, Michael N.(1991). Teaching Literature. New York: Longman. CERVERA, Juan. (1993). Literatura y lengua en la educación infantil. Bilbao: Ediciones Mensajero.

COLLIE, Joanne \& SLATER, Stephen. (1994). Literature in the Language Classroom. A Resource Book of Ideas and Activities. Cambridge: Cambridge University Press.

DAKIN, Julian. (1993). Songs and Rhymes. Harlow: Longman.

ELLIS, Gail \& BREWSTER, Jean. (1991). The Storytelling Handbook for Primary Teachers. New York: Penguin Books.

ESCUDERO MARTíNEZ, Carmen. (1994). Didáctica de la literatura. Murcia: Ed. Compobell, SL.

FRYE, N. (1973). La estructura inflexible de la obra literaria. Madrid: Taurus.

GARCÍA HOZ, Víctor. (1993). Enseñanza y aprendizaje de las lenguas modernas. Madrid: Ediciones Rialp SA.

GARCÍA PADRINO, Jaime y MEDINA, Arturo. (1988). Didáctica de la lengua y la literatura. Madrid: Anaya.

LITTLEWOOD, N. (1986) "Literature in the School Foreign-Language Course." En Brumfit \& Carter 1986: 177-184.

LONG, M.N. (1986). "A Feeling for Language: The Multiple Values of Teaching Literature." En Brumfit \& Carter 1986: 42-60.

LOTT, Bernard. (1986). A Course in English Language and Literature. London: Edward Arnold Publishers.

- -.(1986). A Course in English Language and Literature Tutor's Book. London: Edward Arnold Publishers.

MARTOS, Eloy. (1988). Métodos y diseños de investigación en didáctica de la literatura. Madrid: MEC.

MUÑOZ, Miguel. (1992). La poesía y el cuento en la escuela. (Una metodología para el área de lenguaje en el ciclo medio de E.G.B.). Madrid: La conserjería de educación y cultura de la Comunidad de Madrid.

WRIGHT, Andrew. (1996). Cuenta cuentos. Madrid: Oxford University Press. 
